\title{
Optimization of Metal Inert Gas Welding Process during Joining of Structural Steels- An Overview
}

\author{
Ravindra Kumar Misra ${ }^{1}$, and Rajesh Kumar Porwal ${ }^{2, *}$ \\ ${ }^{1}$ Faculty of Mechanical Engineering, Shri Ramswaroop Memorial University, Lucknow, India \\ ${ }^{2}$ Faculty of Mechanical Engineering, Shri Ramswaroop Memorial University, Lucknow, India
}

\begin{abstract}
Metal Inert Gas welding is a fast, reliable and cost effective technique for joining of different ferrous materials and steels used in the construction of large structures like Fe410WA, IS2062, SS304, AISI1040 and AISI316 etc. To obtain better quality and performance of the steel welded joints, parameter optimisation of metal inert gas welding procedure and weld heat treatment process is carried out. In optimization work and studies, variables of GMAW process like welding voltage and current, speed of welding, WFR (rate of wire feed), GFR (rate of gas flow), type of gas used and effect of heat treatments are kept changing to get best combinations of input parameters for best quality of welded parts. The quality of welds is evaluated in terms of mechanical properties of welded joints like ultimate tensile and yield strength, elongation, microstructure, heat affected zone and defect free weld joints etc. Model and experimental studies are done in different combinations to get best combination of input parameters for steels. Studies by authors have identified the significance of input parameters in ascending order and some of them also quantified the optimal values of the input parameters. Pre and post weld heat treatment of structures is beneficial in improvement of mechanical and fatigue properties.
\end{abstract}

\section{Introduction}

MIGW and its synonyms like GMAW or metal active gas welding (MAG Welding) was developed around late 1940 's. This process was evolved to accelerate welding process that was carried out by the Tungsten inert gas (TIG) Welding. TIG done soundly on thin plates (factually plates melt together without using filler electrode wire), MIGW is more capable and costeffective for thicker work piece welding. In addition to have cost-effective on heavy, thicker aluminum sections, MIG was developed to fabricate better quality welds on different metals and sections, both small and large. MIGW is applicable to all type of steels due to reduced welding time in comparison to other weld processes. MIGW is comparatively easy for adjustment with robotic application and automation too, thus, MIGW became a major element in industry nowadays. In spite of similar metals, MIGW is being used to join dissimilar metals, alloys and non-metals effectively. In the modern age, requirement of similar materials welding is continuously increasing due to its benefits like,

- faster speeds and output, lower distortion,

- eliminating slag removal, elevated weld deposition rate,

- quality welds, elevated strength,

- high depth of penetration, unbroken welding at elevated speeds and
- reduced chances of defective welding, appropriate mechanical properties and

- cost reduction etc.

Generally, GMAW is inappropriate for outdoors for the reason that the flow of the adjoining atmospheric air will disperse the protecting inert gas flow and this will make process complicated, while diminishing the welding quality also. This concern can be eliminated or minimized by escalating the shielding gas flow making process costlier. Generally, shielded MIGW and FCAW (flux cored arc welding) are used for outdoors applications. That is why the use of MIGW in the construction industry is limited. In addition, due to the use of a shielding gas, MIGW is not popular for underwater requirement of welding, but MIGW can be used in space because the weld will not oxidize since there is no oxygen. This paper is an overview on the experimental and simulated optimization [1] of welding parameters performed with steel material.

\section{Methodology \& Parametric Studies}

MIGW is a type of welding where electric arc is created in among the work metal and electrode wire which is consumable type for heating job causing both these to fuse together and solidify into a single joint. Constant voltage type DC power supply is widely used in such applications, moreover, constant current supply systems and AC current systems can also be used. An

\footnotetext{
* Corresponding author: rkmisra77@gmail.com
} 
inert shielding gas is supplied via welding torch partaking the wire electrode of consumable type. Supplied inert gas, shielding the process from oxidation and avoid mixing of contaminants available in the atmospheric air.

Table1. Parameters of MIGW Technique.

\begin{tabular}{|c|c|c|}
\hline $\begin{array}{ll} & \text { Input Parameters } \\
- & \text { Voltage } \\
- & \text { Current } \\
- & \text { WFR } \\
- & \text { GFR } \\
- & \text { Speed of welding } \\
- & \text { NPD } \\
- & \text { Angle b/w Torch-Job } \\
- & \text { Pre \& Post Heating } \\
- & \text { No. of passes } \\
- & \text { Joint Gap \& } \\
& \text { Geometry }\end{array}$ & - & $\begin{array}{ll} & \text { Output Parameters } \\
\text { - } & \text { Yield Strength } \\
\text { - } & \text { Ultimate Tensile } \\
& \text { Strength } \\
\text { - } & \text { Bending Strength } \\
\text { - } & \text { Geometrical } \\
& \text { Parameters like; } \\
\text { - } & \text { Distortion } \\
- & \text { Bead width } \\
\text { - } & \text { Height } \\
- & \text { Penetration }\end{array}$ \\
\hline
\end{tabular}

Welding excellence including mechanical characteristics of the weldments are influenced by different input variable of welding and geometry of the joint. Welding inputs are process specific, control the WDR and characteristics of weldments. Generally, WBG, DOP and overall weld quality parameters are dependent on inputs like current and voltage in welding, (GFR) Gas Flow rate, Number of passes, Surface finish, Gap and joint geometry etc. Process parameters in MIGW being used for steels are optimized using DOE (design of Experiment) and numerical techniques. Superiority of the weldment may be enhanced by optimization [4] of process parameters in MIGW, elimination (or) minimization of the expanses of undertaking number of test/ trials and reduction in the depletion of assets too.

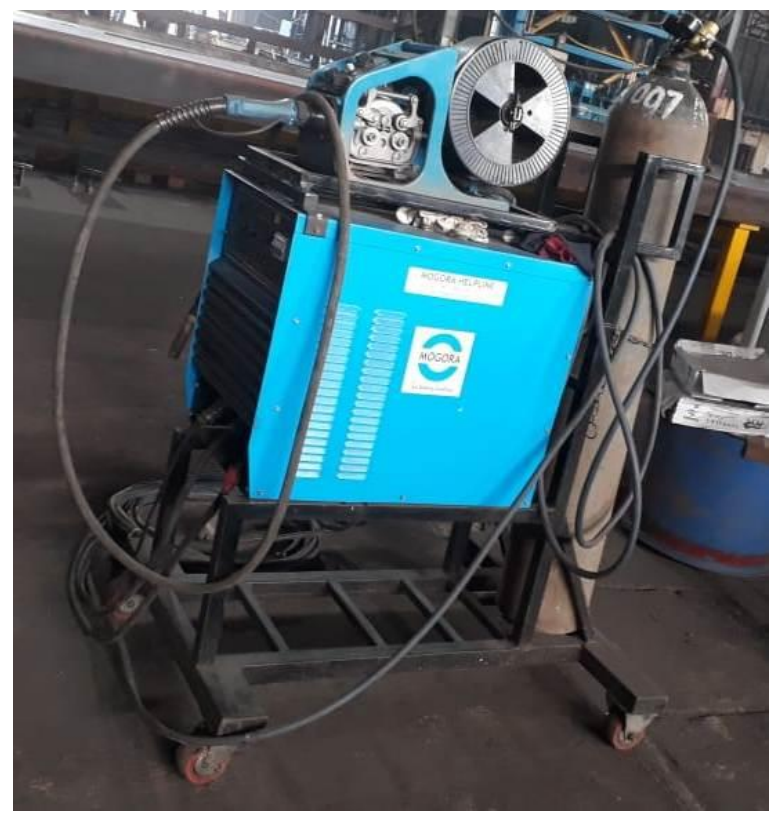

Fig.1. Compacted MIGW Equipment-Portable.

\section{Literature Review}

\subsection{Modelling Studies}

Ganjigatti P. et. al. [2] has undertaken study to establish co-relation among input parameters and response parameters using linear and nonlinear-regression analysis for the collected data by design of experiments using full factorial method. Total 4 approaches are tried in which three were with linear model and one was with non-linear model the best results was with approach one having linear regression equations were in un-coded form. A 3-dimensional computer model is developed by A.B. Murphy et. al. [3] to study thermal histories of MIG welded works. The model can determine temperature distribution, density of current, speed and mass fraction over the complete weld area, work piece and the input data may be used to generate the important properties of weld-ments like stress pattern and micro structural changes. The results shown fair level of agreement with the predicted responses. Generated graphical user interface on a desktop computer may be used to predict different responses providing input parameters. The computer generated plots for the considered properties are shown as under:
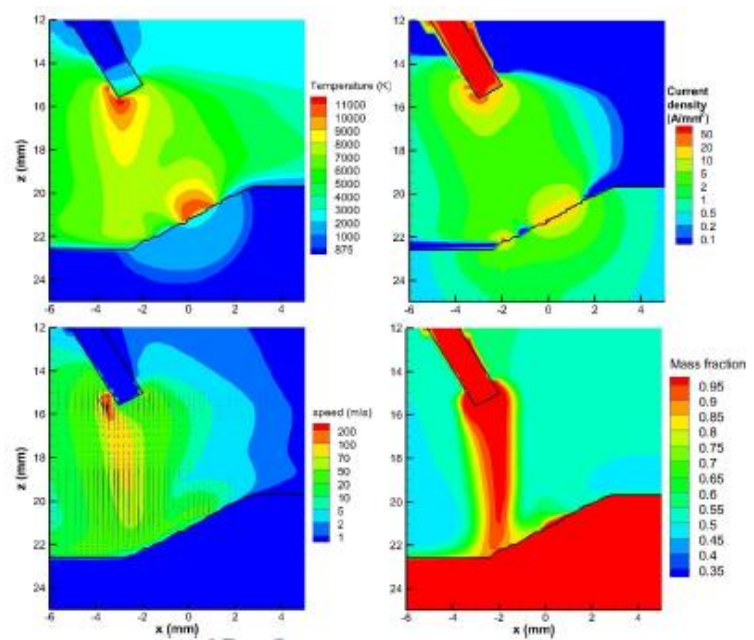

Fig.2. Distribution patterns of temperature, flow speed, current density and mass fraction in the vertical plane through electrode. [2]

\subsection{General Optimisation Studies}

B. Sharma et. al. [5] experimented that if amperage is increased-bead width and penetration increases, if voltage is increased-bead width generally increases and at one best possible voltage the WBW is minimum and penetration is maximum in IS 2062 steel and the increased travel speed the electrode deposition decreases so electrode life increases. Taguchi technique's 16 orthogonal-array and ratio of signal-noise (SNR) of ANOVA used by S.A. Rizvi et. al. [6] to show that the current and voltage affect significantly whereas GFR has immaterial result on tensile strength and for optimum tensile strength welding parameters were found as $27 \mathrm{~V}$, $300 \mathrm{~mm} / \mathrm{min}$ WFR and GFR as $10 \mathrm{l} / \mathrm{min}$. S. Srivastava et.al. [7] applied Design technique BoxBehnken of Response Surface Methodology studied welding of IS 2062 and found that WFR tailed by voltage and speed of 
weld are the sequence of effective parameter among all and least influencing parameter is Gas flow rate with less than two percent errors. Heat affected zone (HAZ) is concluded as most influencing factor by P. Sarin et. al. [8] and contribute about $41.95 \%$ followed by the feed wire rate (WFR) (19.91\%), GFR (5.20\%) and good quality may be achieved by keeping carbon content in ferrous material minimum. S.A. Rizvi et. al. [9] executed Grey relational analysis of Taguchi orthogonal array for optimization of the welding of SS304H and found WFR had the maximum impact followed by voltage $(\mathrm{V})$ and GFR as seen from ANOVA table and observed optimal parameters were voltage of arc $23 \mathrm{~V}$, GFR $25 \mathrm{l} / \mathrm{min}$, and WFR 350 IPM. Fracto-graphy analysis indicated a ductile mode of fracture in both the cases. M.A. Moghaddam et. al. [8] concluded that in multi-criteria modelling of MIGW, BPNN-PSO is highly capable and found average errors of $0.33 \%$ to $0.82 \%$ are found in simulating MIGW process through BPNN model. A survey undertaken by K.Y. Benyounis et. al. [11] reveals enough interest for RSM and ANN in predicting optimization and response and mentioned the requirement of relative study about the results of the techniques used for optimization and suggested that in future focus should be on modelling and optimization techniques which are environment friendly, economical and safe. In the comparative analysis of predicated and experimental values of weld penetration depth in MS C20 material, S.V. Sapakal et. al. [12] confirmed success of optimization techniques of Taguchi and influence of current, voltage and speed parameters. N. Ghosh et. al. [13] used Grey - Taguchi methodology and radiographic test with X-ray and found current is most influencing with optimum values as GFR $20 \mathrm{l} / \mathrm{min}, 100 \mathrm{~A}$ and NPD as $15 \mathrm{~mm}$ and most inferior tensile strength with current GFR $10 \mathrm{l} / \mathrm{min}, 124 \mathrm{~A}$ and NPD $15 \mathrm{~mm}$ for AISI $316 \mathrm{~L}$ austenitic stainless steel. In another study, N. Ghosh et. al. $[14,15]$ studied UTS and PE using L9 orthogonal array of Taguchi methodology on AISI409 ferritic steel materials and observed optimal parametric values as 124 A, $10 \mathrm{l} / \mathrm{min}$ and NPD as $9 \mathrm{~mm}$. Confirmation of results done through experiments. Author has determined optimum combination of parameters using key impact and $\mathrm{S} / \mathrm{N}$ relation plots and established the optimal process variables as GFR $20 \mathrm{l} / \mathrm{min}$, current $100 \mathrm{~A}$, and NPD $9 \mathrm{~mm}$. Proper choice of shielding gas and optimal GFR pays back in the form of improved productivity, weld geometry properties, microstructure, mechanical characteristics in scientific case studies and experiments and reduction in cost incurred towards used gas consumption presented by B. Mvola et. al. [16]. K.P. Babu et. al. [17] developed a mathematical model and undertaken experimentations using factorial design approach to discover direct relation between the welding amperage and speed with respect to deposit area of weld in the weldment of mild steel. NPD and Voltage change straightly with deposit-area of weld and inversely with welding current and speed established by M. Singla et. al. [18] using factorial design approach optimization by developing a mathematical model. Optimal levels of the factors are different for different objectives presented by P. Sonasale [19] using Taguchi's experimental design strategy. Welding amperage has the maximum impact on hardness and tensile properties in the welds of ASTMA29 material tailed by voltage, WFR in optimization undertook by A. Prakash et. al. [20]. V. Sankar et.al. [21] studied the influence of inputparameters like voltage, current and GFR of MIGW on hardness and tensile strength of welded joint made out with AISI 310 material. Grey rational analysis was done to see the most impacting parameters with higher Grey Grade like current as observed in the experiments.

\subsection{Experimental optimization for Mechanical Properties}

Angular distortion was calculated theoretically by A. Narwadkar et. al. [22], found higher with high current and voltage but minimised with high GFR and by optimisation processing cost and time may be saved. Experimental optimization using Taguchi method shown 96.43 percent confidence. Similar exercise in done on a mathematical model using three factor statistical method and full factorial design of two level by P. Kumar [23] and found positive effect of no. of beads or passes (maximum influence) and joint gap, however, time between successive passes has negative effect (minimum influence).

Yield stress of MIG welded AISI 1040 carbon steel was analyzed and Longitudinal direction is having greater yield strength investigated by A. Hooda et. al. [24] using response surface methodology (RSM) and identified gap in the relationship among transverse and longitudinal strength. Observed optimal parameters in the process were $23 \mathrm{~V}$, WFR 350 IPM and GFR as 15 $1 /$ min by S.A. Rizvi et. al. [25] and identified that voltage is having maximum effect, GFR has minimum effect on UTS.

K.R. Jagtap et. al. [26] has studied response in terms of mechanical properties like strength in ultimate tensile and yield state by developing a mathematical model and validation with co-relation coefficient very close to one (0.95) considering input as WFR, Current and No. of passes on IS 2062 E250 steel. The co-relation between input and response are established with the help of linear regression model. To examine the influence of input on response, variance analysis method is adopted and optimization is done through response surface technique.

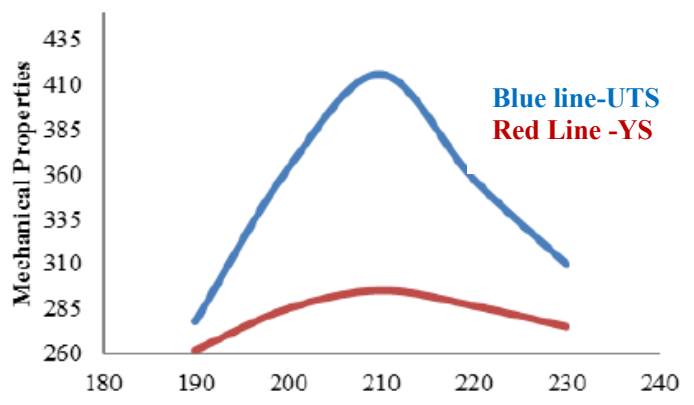

Fig.3. Graph showing effect of welding current. [24] 


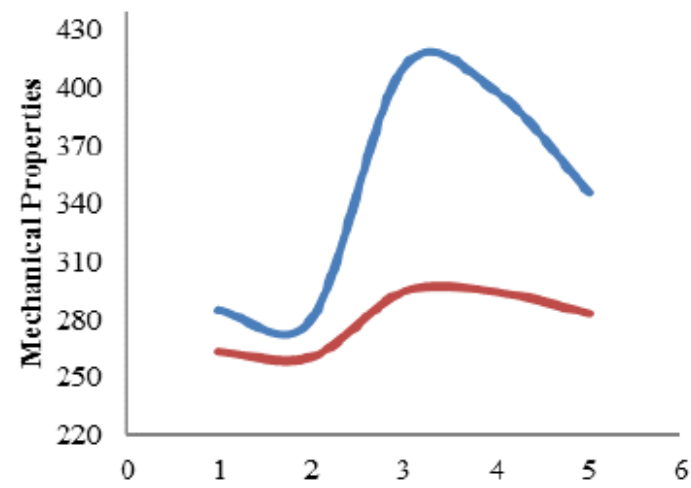

Fig.4. Graph showing effect of Wire Feed Rate ( $\mathrm{mm} / \mathrm{min})$.[24]

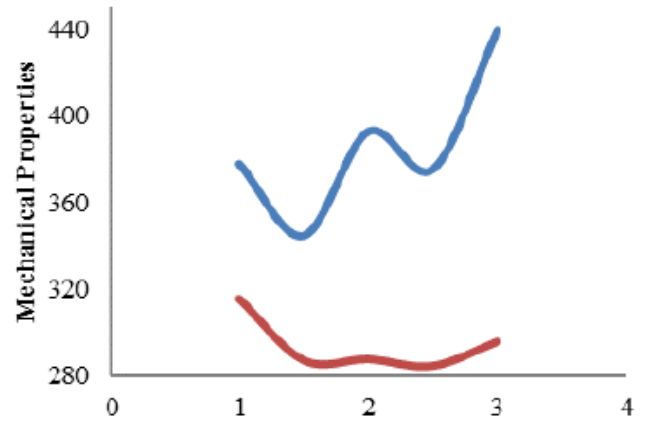

Fig.5. Graph showing effect of Number of Weld Passes. [24]

Wire feed rate is the most important and influential factor having a positive impact on the NPD, welding speed, WFR and surface roughness established by D. Kumar et. al. [27] and concluded that increased wire feed rate increases depth of penetration. Voltage is the most important factor influencing bending strength established by V. Pandhare et. al. [28]. Amperage and speed of welding are main variables influencing tensile properties using Taguchi technique on GMA Welded AISI 1030 mild steel concluded by S.R. Patil et. al. [29].

\subsection{Experimental studies with Preheat Treatments}

Hybrid welding process using fibre laser having $4 \mathrm{~kW}$ power and MIGW simultaneously on 304 Steel and 6061-T6 aluminum alloy is carried out by J. Xue et. al [30] to analyze the joint properties with respect to joint morphology and tensile properties and found that by increasing heat input, molten metal spread over the joint and better intermediate layer developed by providing reinforcement layer along with significant improvement in tensile strength also.

S. Kumar et. al. [31] has identified gap in investigating tensile properties of AISI 1018 steel with one of the variables i.e. preheat temperature and used grey based Taguchi method. Confirmation experiments are further undertaken with different combination of voltage, current and preheat temperature and established that constraints of Taguchi method for multi-objective analysis are over come and optimization of parameters are successfully done with grey based Taguchi method. In grey relational method, grey-relational coefficients (GRC) and grey-relational grades (GRG) are calculated and mean $\mathrm{GRG}$ are plotted with $\mathrm{S} / \mathrm{N}$ ratio to get the contributions of parametric inputs. Preheat temperature is the prime factor to decide percentage elongation and the ultimate tensile strength of the samples.

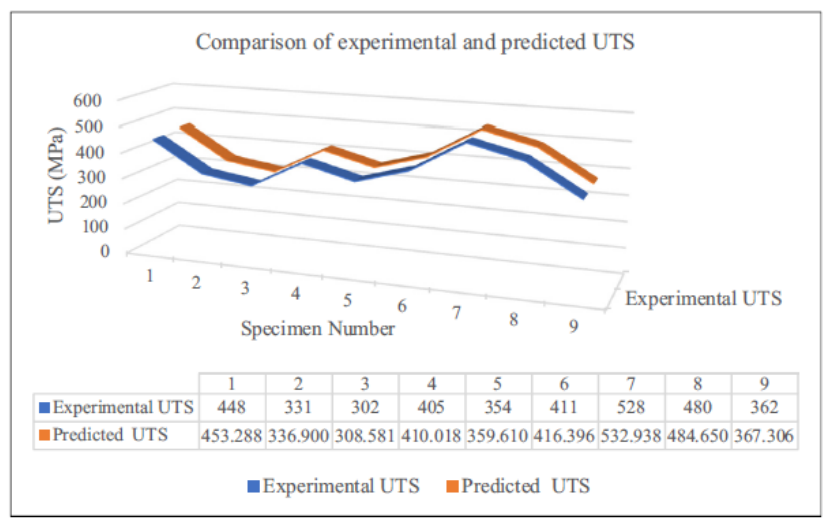

Fig.6. Graph of Experimental Vs. Predicted UTS. [29]

\section{Conclusions:}

Extracts of the review study of optimization of MIG process on steels are summarized as follows:

- MIGW is cost effective and easily optimised as per structure requirement for steels

- Process parameters are optimized to minimise heat affected zone, distortion and

- Improve weld penetration, mechanical properties and overall quality

- Pre/Post-heating temperature is most critical for tensile strength and elongation

- Current, Voltage and Wire feed rate are other most influencing parameters on strength.

\section{References}

1. Satyanarayana, Kosaraju, Anne Venu Gopal, and Popuri Bangaru Babu., IJMMM. 13(2-3), 191-202. (2013).

2. Ganjigatti P. Pratihar D.K. and Roy Choudhury A., I. J. of Adv. Mfg. Tech. 35, 1166 (2008)

3. A.B. Murphy, V. Nguyen, Y. Feng, D.G. Thomas, D. Gunasegaram, App. Math. Mod. S0307-904X (2017)

4. Kosaraju, Satyanarayana, M. Vijay Kumar, and N. Sateesh. Material Today 5,2 5343-5348. (2018)

5. B. Sharma, S. Goyal, J. Adv. Res. ME. Tech. 3(3), 17 (2016)

6. S.A. Rizvi, S.P. Tewari, W. Ali, Int. J. on ET in MPE 1, (2017)

7. S. Srivastava, R.K. Garg, ELSEVIER- J. of MP. 25 296 (2017)

8. P. Sarin, M. Kumar, V.K. Sharma, Int. Con. on Adv. Prod. and Ind. Engg. (2016)

9. S.A. Rizvi and S.P. Tewari, Res. J. of Comp. and app. Res. in ME 7, 189 (2016) 
10. M. AzadiMoghaddam, R. Golmazerji, F. Kolahan, Measurement (2016)

11. K.Y. Benyounis, A.G. Olabi, ELSVIER- Adv. in Engg. Soft. 39, 483 (2008)

12. S.V. Sapakal, M.T. Telsang, Int. J. of Adv. Engg. Res. and Stud. I, 28 (2012)

13. N. Ghosh, P.K. Pal, G. Nandi, ELSEVIER PT 25, 1038 (2016)

14. N. Ghosh, R. Rudrapati, P.K. Pal, G. Nandi, Elsevier MTP 4, 2213, (2017)

15. N. Ghosh, P.K. Pal, G. Nandi, R. Rudrapati, 2017 Elsevier- MTP 5, 1620 (2018)

16. Yogeswara Reddy B, Srinivas Rao J, Suresh Kumar T, Nagarjuna A, Int J. of Inn. Tech. and Exp. Eng., 8(11), (2019)

17. K.P. Babu, M.B. Chennaiah, N.K. Mohan, I-M's J. on ME 61 (2016)

18. M. Singla, D. Singh, D. Deepak, J. of Min. and Mat. Char. \& Engg. 9, 353 (2010)

19. P. Sonasale, IOSR JMCE. 11, 72 (2014)

20. A. Prakash, R.K. Bag, P. Ohdar, S.S. Raju, IJRET.

21. V. Sankar, D. Lawrence, Jayabal, Elsevier MTP. 5, 14309 (2018)

22. A. Narwadkar, S. Bhosle, TAYLOR \& FRANCISMMP (2015)

23. P. Kumar, Int. J. Adv. Engg. Tech. VI, 41 (2015)

24. A. Hooda, A. Dhingra, S. Sharma, Int. J. Mech. Eng. \& Rob. Res. (2012)

25. S.A. Rizvi, W. Ali, Mech. and ME. 22, 1121 (2018)

26. K.R. Jagtapa, M.S. Rojekara, S.V. Dravid, A.R. Deshpande, Elsevier MTP. 4, 7875 (2017)

27. D. Kumar, R.K. Jain, J. Adv. Res. Electro. Engg. Tech. 4, 1 (2017)

28. V. Pandhare, P. Rai, B.K. Lad, S. Das, K. Sabiruddin, Int. J. Mech. Eng. Res. \& Tech. (2016)

29. S.R. Patil, C.A. Waghmare, Int. J. Adv. Engg. Res. Stud. II, 14 (2013)

30. J. Xue, Y. Li, H. Chen, Z. Zhu, J. of MPT. 0136, (2017)

31. S. Kumar, R. Singh, https://doi.org/10.1016/j.measurement.2019.106924 (2019) 